\title{
Reliability of Contralateral Suppression in Evoked Distortion Product Otoacoustic Emissions
}

\author{
Ana Carolina dos Santos ${ }^{10}$ Ludimila Labanca1(i) Larissa Resende Assumpção ${ }^{10}$ \\ Patricia Cotta Mancini ${ }^{10}$ Sirley Alves da Silva Carvalho ${ }^{10}$ Luciana Macedo de Resende ${ }^{10}$ \\ ${ }^{1}$ Department of Speech-Language Pathology and Audiology, \\ Universidade Federal de Minas Gerais, Belo Horizonte, MG, Brazil \\ Int Arch Otorhinolaryngol 2022;26(2):e250-e259.

\begin{abstract}
Address for correspondence Luciana Macedo de Resende, PhD, Departamento de Fonoaudiologia, Universidade Federal de Minas Gerais, Avenida Alfredo Balena, 190, sala 249 - Santa Efigênia, Belo Horizonte, MG - Brazil
\end{abstract} \\ (e-mail: Imacedo.luciana@gmail.com; lucianamr@ufmg.br).
}

\begin{abstract}
Keywords

- cochlear hair cells

- auditory efferent pathway

- reproducibility of results

- hearing loss

- young adult

- noise effects
\end{abstract}

Introduction Distortion product otoacoustic emissions (DPOAE) and their suppression may be considered useful in monitoring cochlear function and the efferent auditory pathway inhibitory effect. Nonetheless, the establishment of reliable parameters of response variations is of great importance.

Objectives To verify the replicability of test and retest in the research of the inhibitory effect of the efferent pathway using contralateral suppressing stimulus during DPOAE recording for clinical applicability.

Methods Cross-sectional study with 48 volunteers, aged 18 to 30 years, with normal audiometric thresholds. The procedures included were audiometric and immittance measures to overrule any conductive or sensorineural conditions and DPOAE recordings without and with contralateral suppression with a $60 \mathrm{dBHL}$ white noise. Distortion product otoacoustic emissions amplitudes were analyzed and compared in both conditions with Wilcoxon test, and the Spearman correlation test was used to assess test-retest reliability.

Results The comparative analysis showed differences between amplitudes in test and retest conditions only in $1,500 \mathrm{~Hz}$ for DPOAE measures with all other tested frequencies showing no differences, and no difference was observed in all recorded frequencies in the test and retest comparison for DPOAE suppression. The degree of correlation between test and retest of DPOAE amplitude was good at $6,000 \mathrm{~Hz}$ and strong $(r>0.880)$ at the other frequencies. For DPOAE with suppression, all frequencies presented strong correlation between test and retest: $1,500 \mathrm{~Hz}(r=0.880), 2,000 \mathrm{~Hz}$ $(r=0.882), 3,000 \mathrm{~Hz}(r=0.940)$, and $6,000 \mathrm{~Hz}(r=0.957)$.

Conclusions The study found good replicability in contralateral suppression of DPOAE with potential clinical applicability, and we recommend conducting the test from $2000 \mathrm{~Hz}$ to higher frequencies for more reliable results. received

October 7, 2020 accepted after revision April 7, 2021

published online

August 30, 2021
DOI https://doi.org/ $10.1055 / \mathrm{s}-0041-1733928$ ISSN 1809-9777.

\footnotetext{
(c) 2021. Fundação Otorrinolaringologia. All rights reserved.

This is an open access article published by Thieme under the terms of the Creative Commons Attribution-NonDerivative-NonCommercial-License, permitting copying and reproduction so long as the original work is given appropriate credit. Contents may not be used for commercial purposes, or adapted, remixed, transformed or built upon. (https://creativecommons.org/ licenses/by-nc-nd/4.0/) Thieme Revinter Publicações Ltda., Rua do Matoso 170, Rio de Janeiro, RJ, CEP 20270-135, Brazil
} 


\section{Introduction}

The pure-tone threshold audiometry is a universally adopted method to monitor the auditory function. ${ }^{1,2}$ However, the audiometry has subjective results and is not flawless, as it depends on both the examiner's attention and the examinee's responses. Moreover, it has low sensitivity to identify subtle cochlear changes that occur before hearing loss is detected in the audiogram. ${ }^{1,2}$

Recording evoked otoacoustic emissions (OAEs) is a reliable, precise, noninvasive method to analyze the cochlear mechanisms. Otoacoustic emissions are sounds originated in the inner ear and picked up in the external acoustic meatus, resulting specifically from the activity of the outer hair cells. ${ }^{1,3,4}$ The OAEs can be spontaneous or evoked-generated by an acoustic stimulus. ${ }^{4}$ The transiently evoked otoacoustic emissions (TEOAEs) are triggered by a short acoustic broad frequency band click in the cochlea, revealing the performance of the whole organ.,4 The distortion-product otoacoustic emissions (DPOAEs) are acoustic energy of cochlear origin resulting from the interaction between two pure tones with different stimulation intensities presented simultaneously (L1 and L2) in neighboring frequencies (f1 and f2). It results in nonlinear responses in the cochlea, which enables specific frequencies of the cochlear activity to be analyzed. ${ }^{4,5}$

Evoked OAEs have higher sensitivity and specificity to monitor the auditory function than the pure-tone threshold audiometry. ${ }^{1}$ Ever since they were discovered, they have been widely used in neonatal hearing screening to help diagnose cases of neural changes and to follow up cochlear function in treatments with ototoxic medications or in exposure to cochlear-damaging agents. ${ }^{6}$ The record of the DPOAE has been used for the differential diagnosis of hearing losses of cochlear origin, as they are sensitive to the first stages of cochlear changes. ${ }^{1,2,7,8}$

The auditory system comprises the integrated afferent and efferent pathways. ${ }^{9}$ The afferent innervation sends information to the brain about the condition of the outer hair cells regarding their tension, length, and stiffness. ${ }^{10}$ Most of the large myelinated efferent fibers start at the superior olivary complex and are projected toward the contralateral cochlea, ending in the outer hair cells, whereas a smaller number of fibers are projected to the ipsilateral cochlea. ${ }^{10,11}$ The efferent innervation, or medial olivocochlear bundle, is responsible for regulating the slow contractions of the outer hair cells, attenuating the quick contractions, and increasing the system's impedance, which promotes the damping and amplitude of the otoacoustic emissions. ${ }^{10}$

The inhibitory effect, or suppression of the OAE, is the action of the fibers of the medial olivocochlear bundle attenuating the cochlear amplification gain and consequently reducing the movement of the cochlear membrane. It takes place when a simultaneous stimulus is used as these emissions are recorded, applied either ipsi- or contralaterally to the tested ear. ${ }^{9,11}$ With this technique, it is possible to assess the medial olivocochlear bundle that participates in the modulation of the otoacoustic emissions, besides the auditory sensitivity, the localization of the sound source, the better detection of the signal when in noise, the selectivity of frequencies, and the cochlear protection function when there is an exaggerated acoustic stimulation. ${ }^{5,11-14}$

Studies $5,12,14-17$ indicate that it is important to investigate the DPOAE amplitude test-retest repeatability, as it is a noninvasive technique that makes it possible to identify differences between the measurement of deviations and true changes, either physiological or pathological, in the auditory monitoring over time. ${ }^{5,12}$ The record of the DPOAE with suppression effect has proved to have great applicability in clinical practice to detect cochlear changes in people exposed to noise or those who suffered some sort of acoustic trauma, ${ }^{2,18}$ and whose auditory thresholds found in the pure-tone threshold audiometry (gold standard examination to detect hearing loss) are within normality standards.

Though there are some peer-reviewed studies already published with DPOAE suppression, there is also a great variability in recording protocols, and no consensus to what would be more feasible to implement in the clinical setting.

To monitor hearing, it is necessary to establish reliable parameters of response variations in normal individuals to use them in patients exposed to harmful ototoxic agents, chemicals, and loud noises ${ }^{6}$; the latter particularly when searching for retrocochlear dysfunctions, such as hidden hearing loss or acquired synaptopathy. Hence, the present study aimed to verify the replicability of the test and retest in the research of the inhibitory effect of the efferent pathway using contralateral suppressing stimulus when picking up the DPOAE for clinical applicability.

\section{Methods}

\section{Study Design and Ethical Aspects}

The present cross-sectional study compared the amplitude records of DPOAEs performed twice without changing the position of the probe, and also twice with contralateral suppression with white noise in the same condition.

The study, as well as the informed consent form, was approved by the Institutional Review Board of the academic institution under evaluation report number 2693169.

\section{Sample}

A total of 48 volunteers-young adults enrolled in various higher education programs-participated in the research. They were 29 females and 19 males, aged 18 to 30 years, with no otologic complaints. The inclusion criteria were having audiometric thresholds up to $25 \mathrm{dBHL}$, bilaterally, at the frequencies from 500 to $8,000 \mathrm{~Hz}$, and having no tympanometric changes, besides signing the informed consent form.

\section{Procedures}

The individuals answered a standardized questionnaire about their hearing condition (auditory complaints, history 
of otitis and traumas, tinnitus, dizziness, etc.), and whether they had undergone otologic surgeries and presented with metabolic diseases.

Then, the acoustic immittance measures were conducted to ensure that there were no conductive auditory problems. The acceptable tympanometry results were those with a type A curve. The air-conduction audiometry was performed at the frequencies of $500,1,000,2,000,3,000,4,000,6,000$, and $8,000 \mathrm{~Hz}$.

The acoustic immittance was performed with a Madsen Otoflex 100 device, model 1,012 (Natus Hearing \& Balance [formerly Otometrics], Taastrus, Denmark), with a $226 \mathrm{~Hz}$ probe; and the audiometry, with a Madsen Astera audiometer (Natus Hearing \& Balance [formerly Otometrics]).

The DPOAE tests were performed with response record protocol $\mathrm{f} 1 / \mathrm{f} 2$ ratio $=1.22$ and intensity of $\mathrm{L} 1=65$ and $\mathrm{L} 2$ $=55 \mathrm{dBSPL}$. The frequencies (f2) assessed were 1,500, 2,000, 3,000 , and $6,000 \mathrm{~Hz}$.

The records were taken twice without changing the position of either the probe or the participants, who were instructed to remain still. Following the noiseless test, another two records of the DPOAE were taken with contralateral suppression. The testing with suppression was performed with white noise at the intensity of $60 \mathrm{dBSPL}^{6}$ transmitted via TDH39 (Huntington, NY, USA) supra-aural earphones, connected to the audiometer, and taking all the necessary caution to not trigger crossover responses. The probe remained in the same position in both tests.

The DPOAEs were considered present when the signal-tonoise ratio (distortion product-noise floor - DP-NF) was equal to $6 \mathrm{dBSPL}$ or higher, and the minimum amplitudes per frequency were also observed ( - Table $\mathbf{1}$ ). The record of the DPOAE was taken with the AuDX device (Bio-Logic Systems Corp., Mundelein, IL, USA ), and the analysis was performed with the Scout OAE software.

Table 1 Pass/fail criteria for the minimum amplitudes per frequency of the distortion product otoacoustic emissions established by the manufacturer (Biologic Co)

\begin{tabular}{|c|c|c|c|c|}
\hline \multicolumn{5}{|c|}{ Pass/Fail Criteria } \\
\hline $\begin{array}{l}\text { f2 Frequency } \\
(\mathrm{Hz})\end{array}$ & DP & And/Or & DP-NF & $\begin{array}{l}\text { Noisy } \\
\text { Message }\end{array}$ \\
\hline 8,000 & -13 & And & 6 & -5 \\
\hline 7,000 & -10 & And & 6 & -5 \\
\hline 6,000 & -7 & And & 6 & -5 \\
\hline 5,000 & -6 & And & 6 & -5 \\
\hline 4,000 & -5 & And & 6 & -5 \\
\hline 3,000 & -8 & And & 6 & -5 \\
\hline 2,000 & -7 & And & 6 & -5 \\
\hline 1,500 & -3 & And & 6 & -5 \\
\hline
\end{tabular}

Abbreviations: DP, distortion product; IEEP, inhibitory effect of the efferent pathway; NF, noise floor.
The inhibitory effect was calculated by subtracting the response obtained in the 'without noise condition from the response obtained in the with noise condition.

\section{Statistical Data Analysis}

The descriptive results were presented through measures of dispersion and variability for the continuous variables and frequency analysis for the categorical variables. Continuous variables of interest were tested for normality with Kolmogorov-Smirnov test and showed a non-normal distribution. The nonparametric Wilcoxon test was used to compare the values of the DPOAE measures of both the right and left ears, with and without noise, besides the DPOAE test and retest with and without noise. The values of $p<0.05$ were considered significant. The reliability of the test was assessed by the intraclass correlation coefficient (ICC). The interpretation of the magnitude of the concordance estimators ICC was 0 to 0.50 poor; 0.51 to 0.75 moderate; 0.76 to 0.90 good, and $>0.90$ excellent reliability.

\section{Results}

A total of 48 young students-29 (60\%) female and 19 (40\%) male-were included in the study; the mean age was 22 years (standard deviation 2.5 years), with the minimum being 18 and maximum 30 years. All the individuals included in the study had hearing thresholds better than $25 \mathrm{dBHL}$ in all tested frequencies in the audiometric examination.

There was no statistical difference $(p>0.05)$ when comparing the results of the otoacoustic emissions of the right and left ears (Appendices $\mathbf{1}$ and $\mathbf{2}$ ) according to the Wilcoxon test. Given such results, the DPOAE test and retest results were analyzed, regardless of the ear. Hence, 96 ears were included in the analysis of the results.

The comparative analysis for test and retest of the DPOAE amplitudes indicated a difference only at the $1,500 \mathrm{~Hz}$ frequency. There was no difference $(p>0.05)$ at the other tested frequencies $(2,000 \mathrm{~Hz}, 3,000 \mathrm{~Hz}$, and $6,000 \mathrm{~Hz})$ according to the Wilcoxon test. (-Fig. 1A and - Appendix 3).

The comparative analysis for test and retest of the DPOAE amplitudes with suppression effect did not indicate any statistical difference $(p>0.05)$ according to the Wilcoxon test (-Fig. 1B and - Appendix 4), neither did the comparison of the values of the inhibitory effect of the efferent pathway in test and retest $(p>0.05)$ (- Fig. 2 and - Appendix 4).

The degree of correlation between the test and retest for the amplitude of distortion product was good at $6,000 \mathrm{~Hz}$ and excellent at the other frequencies, according to the ICC. The correlation between test and retest of the distortion product with suppression was excellent at all assessed frequencies: $1,500 \mathrm{~Hz}, 2,000 \mathrm{~Hz}, 3,000 \mathrm{~Hz}$, and $6,000 \mathrm{~Hz}$. The results indicate the presence of a correlation between the IEEP test and retest for the $1,500 \mathrm{~Hz}$ and $2,000 \mathrm{~Hz}$ frequencies. The correlation was moderate for $1,500 \mathrm{~Hz}$ and poor for $2,000 \mathrm{~Hz}$ (-Table 2). 


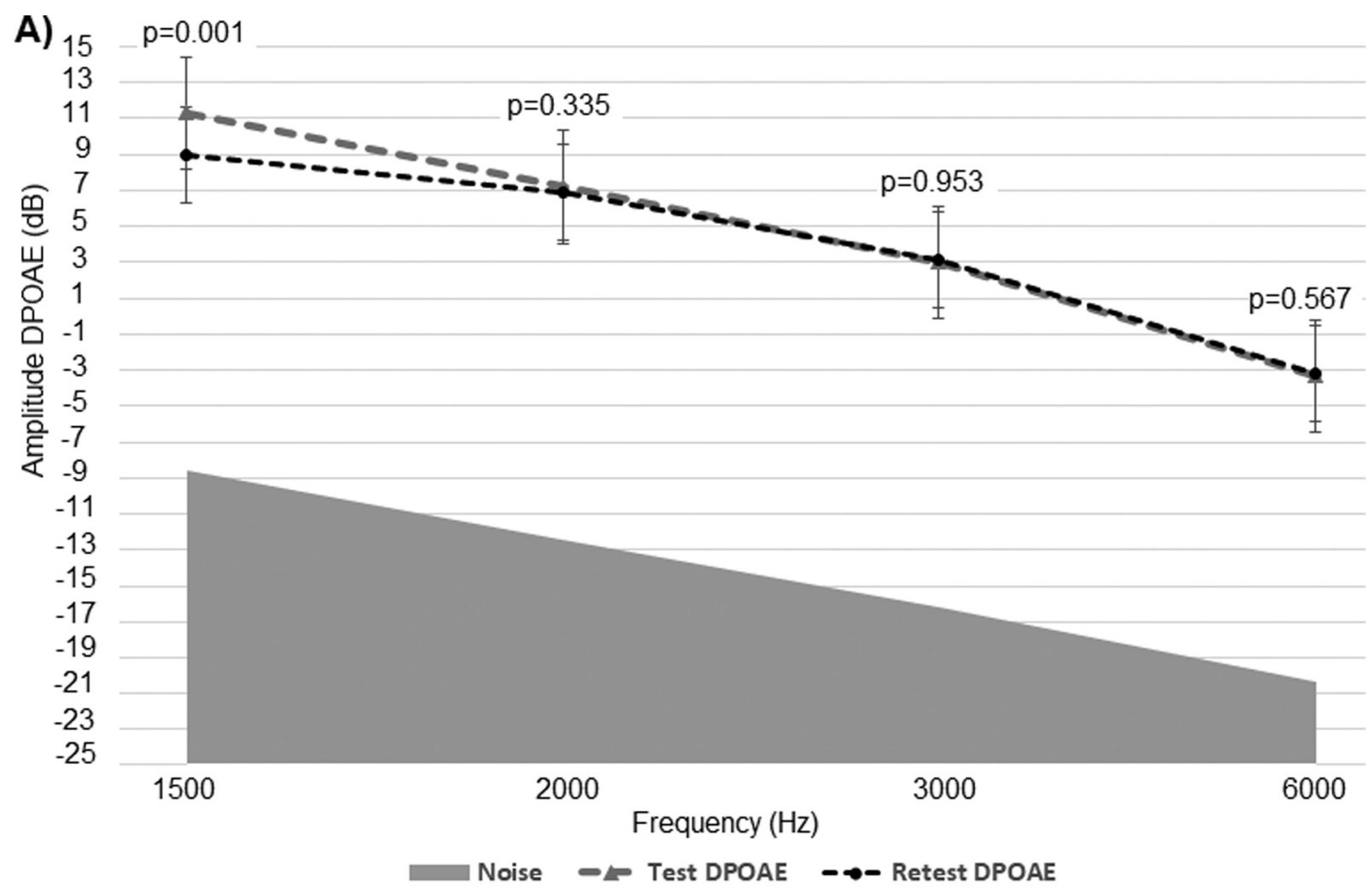

B)

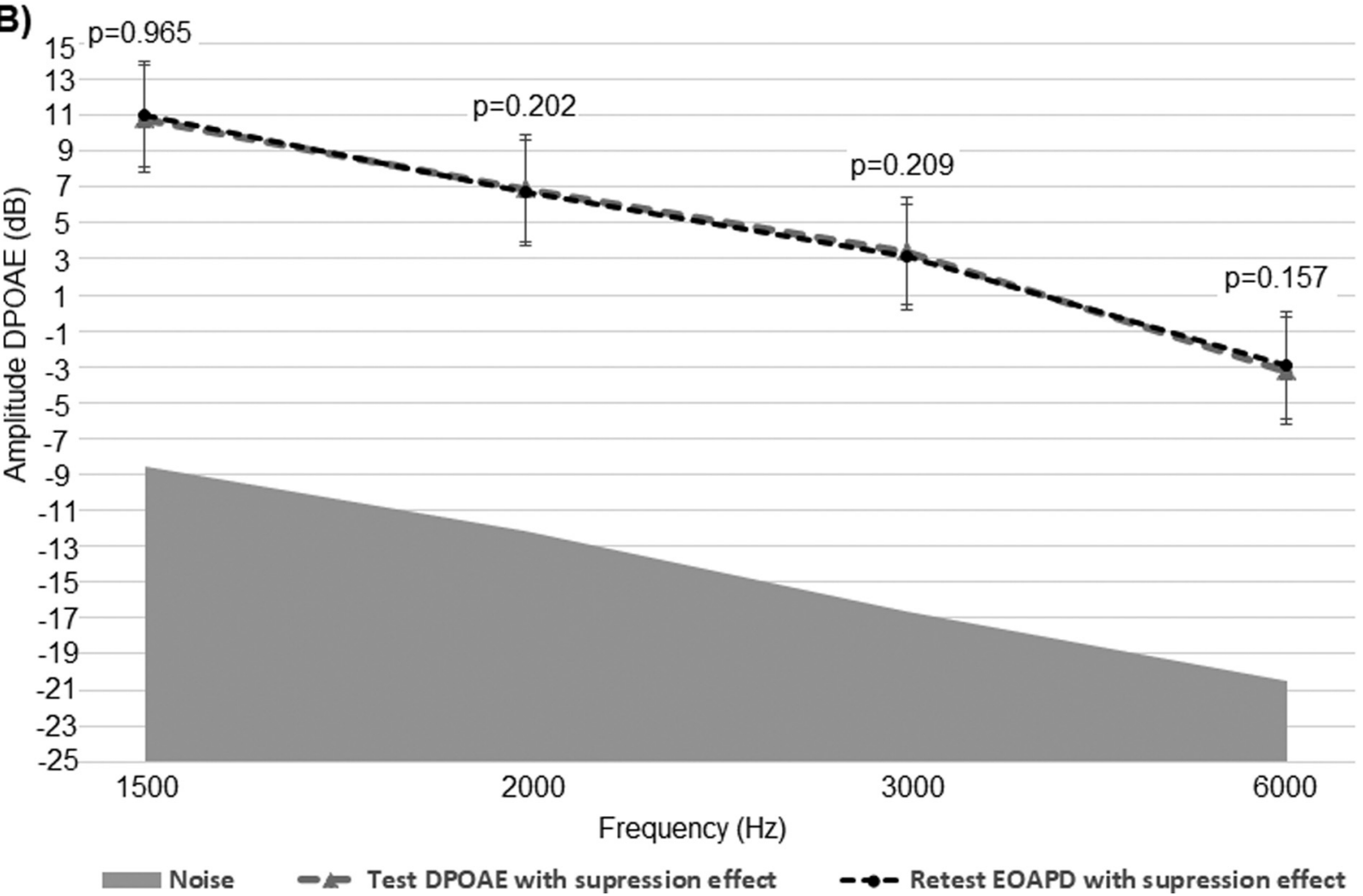

Fig. 1 Test and retest distortion products otoacoustic emissions' amplitudes and distortion product otoacoustic emissions' amplitudes in the test and retest with suppressing noise ( $n=96$ ears)

\section{Discussion}

The present study investigated the test-retest reliability of the DPOAE amplitudes, as well as the contralateral inhibition of the DPOAE. Regarding the amplitude of the distortion products without contralateral stimulation in test and retest, this study's findings showed a statistical difference, only at the $1,500 \mathrm{~Hz}$ frequency. There are reports in the literature that the 


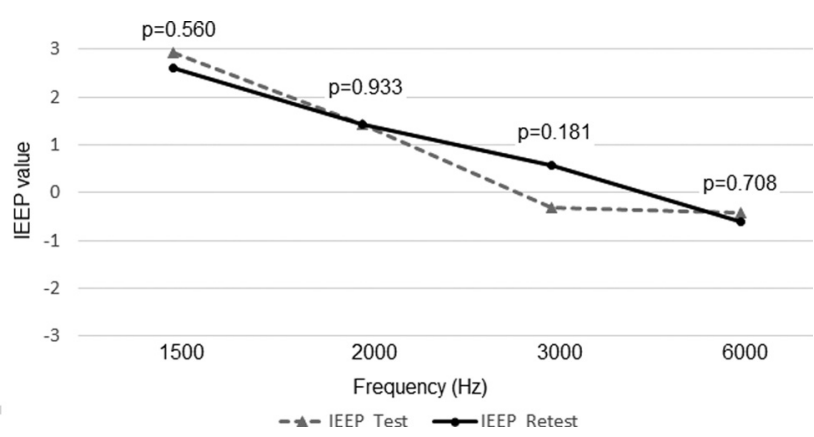

Fig. 2 Test and retest values of the inhibitory effect of the efferent pathway $(n=96$ ears)

DPOAE amplitudes were similar between sessions, indicating a good test-retest reliability. ${ }^{5,12,19}$ Kalaiah et al. $(2018)^{5}$ suggest that a variation in the frequencies is expected when the test is repeated. Additionally, studies report an indication of intraand intersession variability in the DPOAE amplitudes. There have been variations between the frequencies with no tendency observed for it to happen.,12

Zhao and Stephens $(1999)^{15}$ researched the DPOAE testretest to examine the various sources that affect the shortand long-term variability. The authors verified that there were no significant changes in the DPOAE amplitudes in four recording sessions performed in the study. The replicability found was very good; however, in some cases, the general tracing of the distortion products curves was not precisely reproduced at frequencies below $1,000 \mathrm{~Hz}$. Moreover, they reported that in one subject the background noise contributed to the low reliability at the low-frequency band.

Roede et al. $(1993)^{16}$ researched the repeatability of the DPOAE in humans with normal hearing and reported that, in general, the DPOAE amplitudes varied more at frequencies below $1,000 \mathrm{~Hz}$ and above $6,000 \mathrm{~Hz}$ than at the medium-frequency region. Furthermore, they found greater variability around $2,000 \mathrm{~Hz}$ in approximately one third of the individuals, and this variability increased in lower levels of stimulus. These findings corroborate the ones found in the present research with a greater variation observed in the $1,500 \mathrm{~Hz}$ frequency.

Another study, by Guedes et al. (2002), ${ }^{6}$ found greater variation in the high-frequency amplitudes $(6,000 \mathrm{~Hz}$ and $8,000 \mathrm{~Hz})$ than in low frequencies $(1,000 \mathrm{~Hz}$ and $2,000 \mathrm{~Hz})$, indicating that these would be the frequencies most affected at first by ototoxic agents, chemicals, and noise, precociously showing the involvement of the outer hair cells.

The variation of the low-frequency DPOAE amplitudes can be caused by noise levels generated by the environment or the person. ${ }^{15,16}$ Nevertheless, it must be pointed out that, in the present study, factors that might interfere with the test-retest reliability were controlled. No patient had changes in their hearing or in the middle ear function. The tests were conducted in an acoustically treated room, excluding environmental noises. The participants were seated in comfortable chairs and were instructed not to swallow or move during the tests. The otoacoustic emissions probe was stable; it was correctly adjusted in the outer auditory canal only once, and then its stability remained constant. The protocol used for the level of DPOAE stimulus complied with the recommendations in the literature ${ }^{16}$ to avoid the slightest variability in the responses. Therefore, it is unlikely that the variables mentioned interfered with variation in amplitude at the $1,500 \mathrm{~Hz}$ frequency, or in any other moment of this study.

Test-retest of DPOAE recording without noise suppression was very important to be stablished prior to the analysis of DPOAE suppression test-retest results.

Kumar et al. (2013) $)^{12}$ and Kalaiah et al. $(2018)^{5}$ found low test-retest reliability in the contralateral stimulation of the DPOAE. They attributed this result to the large confidence intervals for the DPOAE inhibition magnitude, ${ }^{5,12,14}$ the attentional state of the participant during the contralateral acoustic stimulation, ${ }^{5}$ and the fine structure measurements. ${ }^{5,14}$ Kalaiah et al. $(2018)^{5}$ reports in their study that the main reason for the poor repeatability of the DPOAE inhibition is the lower frequency of DPOAE measurement resolution at fixed frequencies, suggesting that the measurements at discrete frequencies may not be reliable, especially when the tests are not conducted in a single clinical session. On the other hand, in the present study, no differences were found with statistical significance regarding the amplitude of the distortion products with contralateral stimulation, neither was there any statistical difference in the comparison of the inhibitory effect value of the efferent pathway in the test and retest conditions, which showed a positive finding for its clinical application.

In the present study, the degree of correlation between the test and retest of the distortion products amplitude was

Table 2 Correlation coefficient between test and retest conditions of the distortion product otoacoustic emissions amplitudes with and without suppression, and the inhibitory effect of the efferent pathway

\begin{tabular}{|l|l|l|l|l|l|}
\hline & & $1,500 \mathrm{~Hz}$ & $2,000 \mathrm{~Hz}$ & $3,000 \mathrm{~Hz}$ & $6,000 \mathrm{~Hz}$ \\
\hline \multirow{2}{*}{ DP } & Degree of correlation (test-retest) & 0.761 & 0.973 & 0.957 & 0.960 \\
\cline { 2 - 6 } & $P$-value & $<0.001$ & $<0.001$ & $<0.001$ & $<0.001$ \\
\hline \multirow{2}{*}{ DP with suppression } & Degree of correlation (test-retest) & 0.930 & 0.929 & 0.974 & 0.979 \\
\cline { 2 - 6 } & $P$-value & $<0.001$ & $<0.001$ & $<0.001$ & $<0.001$ \\
\hline \multirow{2}{*}{ EEEP } & Degree of correlation (test-retest) & 0.563 & 0.464 & 0.289 & 0.281 \\
\cline { 2 - 5 } & $P$-value & 0.010 & 0.033 & 0.128 & 0.153 \\
\hline
\end{tabular}

Abbreviations: DP, distortion product; IEEP, inhibitory effect of the efferent pathway.

$\mathrm{p}$-value $=$ significance probability (intraclass correlation coefficient). 
good at the $6,000 \mathrm{~Hz}$ frequency, and excellent for the other tested frequencies, as shown in - Table $\mathbf{2}$. As for the test and retest of the distortion product with contralateral stimulation, the correlation was excellent at all tested frequencies (ICC $>0.90$ ). These findings corroborate those in the study of Kalaiah et al. (2018), ${ }^{5}$ who reported that the intrasession reliability was greater at the frequencies of $2,380 \mathrm{~Hz}$ and $6,726 \mathrm{~Hz}$, indicating that the DPOAE inhibition is reliable when measured at medium and high frequencies.

In this study, the correlation between the IEEP in test and retest was moderate for $1,500 \mathrm{~Hz}$ and poor for $2,000 \mathrm{~Hz}$, and in $3,000 \mathrm{~Hz}$ and $6,000 \mathrm{~Hz}$, there was no correlation. This result shows that maybe the IEPP is not the best parameter for analyses of the suppression effect. On the other hand, findings of the present study showed excellent test-retest repeatability for the amplitude of DPOAEs with suppression, and this parameter is good and reliable for suppression effect analysis. ${ }^{5}$

Other studies ${ }^{16,17,20}$ also found high DPOAE test-retest repeatability at medium- and high-frequency bands. Franklin et al. $(1992)^{17}$ revealed good repeatability at the frequencies of $2,000 \mathrm{~Hz}$ to $8,000 \mathrm{~Hz}$, which confirms the DPOAE applicability to analyze the high-frequency region of the cochlea and monitor the hearing in individuals at high risk of auditory dysfunction and are also similar to the findings in the present study.

The usefulness of DPOAE suppression includes the identification of early retrocochlear dysfunction, particularly derived from noise exposure and acquired synaptopathies.

The presence of good repeatability of DPOAE with contralateral suppressing stimulus in individuals with normal hearing, found and described in this study, proves this technique as a powerful tool to be implemented in routine clinical practice. Also, it was relevant to establish parameters that will enable the OAE responses to be compared with individuals with discrete cochlear changes - specifically those taking place at higher frequencies, a region where the TEOAEs cannot identify auditory changes. Furthermore, it makes it possible to investigate the integrity of the medial olivocochlear bundle and achieve an early diagnosis involving dysfunctions derived from different etiologies such as those associated with noise exposure in clinical environments.

\section{Conclusion}

The contralateral suppression of the amplitude of DPOEs presented excellent replicability. Thus, it is fair to state that its application proved possible and reliable in clinical practice to evaluate the cochlear and retrocochlear function. It is recommended, with the protocol used in this research, to start DPOAE suppression testing at the $2,000 \mathrm{~Hz}$ frequency to obtain better results.

\section{Funding}

Conselho Nacional de Desenvolvimento Científico e Tecnológico (Grant/Award Number: 309144/2018) and Coordenação de Aperfeiçoamento de Pessoal de Nível Superior (CAPES - Grant/Award Number: 001).
Conflict of Interests

The authors declare that there is no conflict of interests.

\section{References}

1 Vallejo JC, Silva MN, Oliveira JAA, et al. Deteç̧ão precoce de ototoxicidade usando emissões otoacústicas produtivas de distorção. Rev Bras Otorrinolaringol 2001;67(06):845-851

2 Ramos N, Aita ADC, Siqueira LP, Aita FS. O uso de emissões otoacústicas como ferramenta auxiliar no diagnóstico de efeitos da exposição ao ruído. Rev Bras Saúde Ocup 2011;36(124):282-287

3 Kemp DT. Stimulated acoustic emissions from within the human auditory system. J Acoust Soc Am 1978;64(05):1386-1391

4 Couto CM, Carvallo RMM. O efeito das orelhas externa e média nas emissões otoacústicas. Rev Bras Otorrinolaringol 2009;75(01): 15-23

5 Kalaiah MK, Lasrado A, Pinto N, Shastri U. Short Term Test-Retest Reliability of Contralateral Inhibition of Distortion Product Otoacoustic Emissions. J Audiol Otol 2018;22(04):189-196

6 Guedes MC, Passos SN, Gomez MVSG, Bento RF. Estudo da reprodutibilidade das emissões otoacústicas em indivíduos normais. Rev Bras Otorrinolaringol 2002;68(01):34-38

7 Marques FP, Costa EA. Exposição ao ruído ocupacional: alterações no exame de emissões otoacústicas. Rev Bras Otorrinolaringol 2006;72(03):362-366

8 Leme VN. Emissões Otoacústicas: Efeito da estimulação acústica contralateral e bilateral na função do sistema auditivo eferente. Dissertação: Faculdade de Medicina da Universidade de São Paulo; 2009

9 Burguetti FAR, Carvallo RMM. Sistema auditivo eferente: efeito no processamento auditivo. Rev Bras Otorrinolaringol 2008;74(05): 737-745

10 Oliveira JRM, Fernandes JC, Costa Filho OA. Influência da idade na atividade do sistema eferente nas propriedades mecânicas da cóclea de ouvintes normais. Rev Bras Otorrinolaringol (Engl Ed) 2009;75(03):340-344

11 Guinan JJ Jr. Olivocochlear efferents: anatomy, physiology, function, and the measurement of efferent effects in humans. Ear Hear 2006;27(06):589-607

12 Kumar UA, Methi R, Avinash MC. Test/retest repeatability of effect contralateral acoustic stimulation on the magnitudes of distortion product ototacoustic emissions. Laryngoscope 2013;123 (02):463-471

13 Mor R, Azevedo MF. Emissões otoacústicas e sistema olivococlear medial: pacientes com zumbido sem perda auditiva. Pró-Fono Rev Atual Cient 2005;17(03):283-292

14 Mishra SK, Abdala C. Stability of the medial olivocochlear reflex as measured by distortion product otoacoustic emissions. J Speech Lang Hear Res 2015;58(01):122-134

15 Zhao F, Stephens D. Test-retest variability of distortion-product otoacoustic emissions in human ears with normal hearing. Scand Audiol 1999;28(03):171-178

16 Roede J, Harris FP, Probst R, Xu L. Repeatability of distortion product otoacoustic emissions in normally hearing humans. Audiology 1993;32(05):273-281

17 Franklin DJ, McCoy MJ, Martin GK, Lonsbury-Martin BL. Test/retest reliability of distortion-product and transiently evoked otoacoustic emissions. Ear Hear 1992;13(06):417-429

18 Abdala C, Ma E, Sininger YS. Maturation of medial efferent system function in humans. J Acoust Soc Am 1999;105(04):2392-2402

19 Wagner W, Heppelmann G, Vonthein R, Zenner HP. Test-retest repeatability of distortion product otoacoustic emissions. Ear Hear 2008;29(03):378-391

$20 \mathrm{Ng}$ IH-Y, McPherson B. Test-Retest Reliability of Distortion Product Otoacoustic Emissions in the 1 to $7 \mathrm{kHz}$ Range. Audiol Med 2005;3(02):108-115 
Reliability of Contralateral Suppression in Evoked Distortion Product Otoacoustic Emissions Santos et al.

Appendix 1 Comparative analysis of the left and right ears' distortion product otoacoustic emissions

\begin{tabular}{|c|c|c|c|c|c|c|c|c|c|}
\hline \multirow{3}{*}{$\begin{array}{l}\text { Descriptive } \\
\text { statistics }\end{array}$} & \multicolumn{9}{|c|}{$1,500 \mathrm{~Hz}$} \\
\hline & \multicolumn{2}{|l|}{$D P(d B)$} & \multirow[t]{2}{*}{$P$-value } & \multicolumn{2}{|l|}{$N F(d B)$} & \multirow[t]{2}{*}{$P$-value } & \multicolumn{2}{|c|}{ DP-NF (dB) } & \multirow[t]{2}{*}{$P$-value } \\
\hline & RE & LE & & RE & LE & & RE & LE & \\
\hline Mean & 11.45 & 11.13 & 0.590 & -8.45 & -8.75 & 0.587 & 19.98 & 19.89 & 0.743 \\
\hline Median & 14.00 & 13.10 & & -8.15 & -8.25 & & 21.30 & 20.20 & \\
\hline Minimum & -17.30 & -21.10 & & -19.00 & -18.00 & & 0.10 & -3.10 & \\
\hline \multirow[t]{4}{*}{ Maximum } & 23.80 & 24.20 & & 9.70 & 1.00 & & 33.90 & 37.20 & \\
\hline & \multicolumn{9}{|c|}{$2,000 \mathrm{~Hz}$} \\
\hline & \multicolumn{2}{|l|}{$\mathrm{DP}(\mathrm{dB})$} & \multirow[t]{2}{*}{$P$-value } & \multicolumn{2}{|l|}{$N F(d B)$} & \multirow[t]{2}{*}{$P$-value } & \multicolumn{2}{|c|}{ DP-NF (dB) } & \multirow[t]{2}{*}{$P$-value } \\
\hline & RE & LE & & RE & LE & & RE & LE & \\
\hline Mean & 7.43 & 6.94 & 0.249 & -12.40 & -12.55 & 1.000 & 19.83 & 19.49 & 0.357 \\
\hline Median & 8.00 & 8.20 & & -13.80 & -12.90 & & 19.35 & 20.00 & \\
\hline Minimum & -13.60 & -16.60 & & -17.50 & -18.60 & & 0.60 & 1.00 & \\
\hline \multirow[t]{4}{*}{ Maximum } & 22.20 & 20.80 & & -3.50 & -0.80 & & 34.20 & 34.00 & \\
\hline & \multicolumn{9}{|c|}{$3,000 \mathrm{~Hz}$} \\
\hline & \multicolumn{2}{|l|}{$\mathrm{DP}(\mathrm{dB})$} & \multirow[t]{2}{*}{$P$-value } & \multicolumn{2}{|l|}{$N F(d B)$} & \multirow[t]{2}{*}{$P$-value } & \multicolumn{2}{|c|}{ DP-NF (dB) } & \multirow[t]{2}{*}{$P$-value } \\
\hline & RE & LE & & RE & LE & & RE & LE & \\
\hline Mean & 3.28 & 2.76 & 0.498 & -16.35 & -16.12 & 0.775 & 19.27 & 18.88 & 0.685 \\
\hline Median & 4.35 & 3.70 & & -16.85 & -17.20 & & 20.40 & 19.65 & \\
\hline Minimum & -16.80 & -17.30 & & -23.90 & -22.50 & & -17.60 & -5.40 & \\
\hline \multirow[t]{4}{*}{ Maximum } & 16.80 & 15.30 & & 4.00 & -5.50 & & 35.50 & 34.30 & \\
\hline & \multicolumn{9}{|c|}{$6,000 \mathrm{~Hz}$} \\
\hline & \multicolumn{2}{|l|}{$\mathrm{DP}(\mathrm{dB})$} & \multirow[t]{2}{*}{$P$-value } & \multicolumn{2}{|l|}{$N F(d B)$} & \multirow[t]{2}{*}{$P$-value } & DP-NF & & $P$-value \\
\hline & RE & $\mathrm{LE}$ & & RE & LE & & RE & LE & \\
\hline Mean & -2.90 & -3.73 & 0.800 & -20.44 & -20.30 & 0.293 & 17.54 & 16.36 & 0.767 \\
\hline Median & -3.30 & -4.40 & & -21.85 & -21.50 & & 18.85 & 17.85 & \\
\hline Minimum & -30.20 & -27.10 & & -29.10 & -28.00 & & -5.90 & -4.60 & \\
\hline Maximum & 24.90 & 13.10 & & -11.60 & -10.70 & & 38.50 & 38.20 & \\
\hline
\end{tabular}

Abbreviations: DP, Distortion product amplitude; LE, left ear; NF, Noise floor; RE, right ear; p-value (Wilcoxon test). 
Reliability of Contralateral Suppression in Evoked Distortion Product Otoacoustic Emissions Santos et al. 257

Appendix 2 Comparative analysis of distortion product otoacoustic emissions with the right and left ear suppression effect

\begin{tabular}{|c|c|c|c|c|c|c|c|c|c|c|c|c|}
\hline \multirow{3}{*}{$\begin{array}{l}\text { Descriptive } \\
\text { statistics }\end{array}$} & \multicolumn{12}{|c|}{$1,500 \mathrm{~Hz}$} \\
\hline & \multicolumn{2}{|l|}{$\mathrm{DP}(\mathrm{dB})$} & \multirow[t]{2}{*}{$P$-value } & \multicolumn{2}{|l|}{$N F(d B)$} & \multirow[t]{2}{*}{$P$-value } & \multicolumn{2}{|c|}{ DP-NF (dB) } & \multirow[t]{2}{*}{$P$-value } & \multicolumn{2}{|c|}{ IEEP (dB) } & \multirow[t]{2}{*}{$P$-value } \\
\hline & RE & LE & & RE & LE & & RE & LE & & RE & LE & \\
\hline Mean & 11.18 & 10.41 & 0.266 & -6.08 & -6.34 & 0.626 & 17.26 & 16.75 & 0.448 & 2.72 & 3.13 & 0.770 \\
\hline Median & 13.05 & 12.85 & & -5.75 & -6.45 & & 18.35 & 16.90 & & 2.70 & 2.75 & \\
\hline Minimum & -13.70 & -14.90 & & -15.80 & -17.80 & & -4.40 & 0.60 & & -9.00 & -6.00 & \\
\hline \multirow[t]{4}{*}{ Maximum } & 23.80 & 23.40 & & 4.30 & 9.20 & & 39.60 & 34.90 & & 14.30 & 16.40 & \\
\hline & \multicolumn{12}{|c|}{$2,000 \mathrm{~Hz}$} \\
\hline & \multicolumn{2}{|l|}{$\mathrm{DP}(\mathrm{dB})$} & \multirow[t]{2}{*}{$P$-value } & \multicolumn{2}{|l|}{$N F(d B)$} & \multirow[t]{2}{*}{$P$-value } & \multicolumn{2}{|c|}{ DP-NF (dB) } & \multirow[t]{2}{*}{$P$-value } & \multicolumn{2}{|c|}{ IEEP (dB) } & \multirow[t]{2}{*}{$P$-value } \\
\hline & RE & LE & & RE & LE & & RE & LE & & RE & LE & \\
\hline Mean & 7.18 & 6.61 & 0.488 & -11.16 & -11.50 & 0.512 & 18.33 & 18.12 & 0.828 & 1.50 & 1.38 & 0.580 \\
\hline Median & 6.80 & 7.25 & & -11.15 & -11.90 & & 17.30 & 16.75 & & 1.60 & 1.35 & \\
\hline Minimum & -8.40 & -10.40 & & -19.00 & -18.10 & & 6.10 & 2.50 & & -8.10 & -6.90 & \\
\hline \multirow[t]{4}{*}{ Maximum } & 22.30 & 21.00 & & 1.80 & 0.00 & & 38.00 & 37.00 & & 15.10 & 11.50 & \\
\hline & \multicolumn{12}{|c|}{$3,000 \mathrm{~Hz}$} \\
\hline & \multicolumn{2}{|l|}{$\mathrm{DP}(\mathrm{dB})$} & \multirow[t]{2}{*}{$P$-value } & \multicolumn{2}{|l|}{$N F(d B)$} & \multirow[t]{2}{*}{$P$-value } & \multicolumn{2}{|c|}{ DP-NF (dB) } & \multirow[t]{2}{*}{$P$-value } & \multicolumn{2}{|c|}{ IEEP (dB) } & $P$-value \\
\hline & RE & LE & & RE & LE & & RE & LE & & RE & LE & \\
\hline Mean & 4.44 & 2.39 & 0.069 & -16.28 & -16.23 & 0.985 & 19.94 & 18.83 & 0.859 & -0.68 & 0.05 & 0.254 \\
\hline Median & 5.20 & 3.05 & & -17.40 & -17.05 & & 19.70 & 19.80 & & -0.25 & 0.40 & \\
\hline Minimum & -15.70 & -31.50 & & -23.70 & -22.20 & & -18.30 & -11.40 & & -17.20 & -14.20 & \\
\hline Maximum & 21.60 & 15.50 & & 3.00 & -3.60 & & 37.20 & 31.10 & & 8.60 & 11.60 & \\
\hline & $6,000 \mathrm{H}$ & & & & & & & & & & & \\
\hline & $\mathrm{DP}(\mathrm{dB})$ & & $P$-value & $N F(d B)$ & & $P$-value & DP-NF ( & & $P$-value & IEEP (dB & & $P$-value \\
\hline & RE & LE & & RE & LE & & RE & LE & & RE & LE & \\
\hline Mean & -2.71 & -3.80 & 0.253 & -20.19 & -21.06 & 0.251 & 17.47 & 17.26 & 0.984 & 0.07 & -0.90 & 0.597 \\
\hline Median & -2.70 & -4.45 & & -21.20 & -21.05 & & 18.60 & 18.35 & & -0.10 & -0.45 & \\
\hline Minimum & -24.20 & -25.30 & & -30.70 & -30.60 & & 2.40 & -5.10 & & -9.50 & -11.90 & \\
\hline Maximum & 25.00 & 11.60 & & -10.80 & -11.90 & & 38.60 & 34.40 & & 12.20 & 8.50 & \\
\hline
\end{tabular}

Abbreviations: DP, distortion product amplitude; IEEP, inhibitory effect of the efferent pathway; LE, left ear; NF, noise floor; RE, right ear; S, suppression.

p-value (Wilcoxon test). 


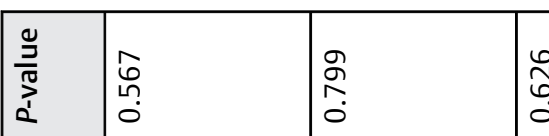

$\underset{\mathscr{W}}{\stackrel{\circ}{\circ}}$

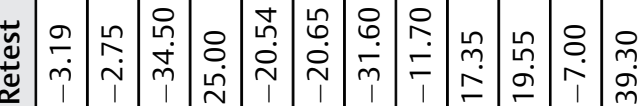

종

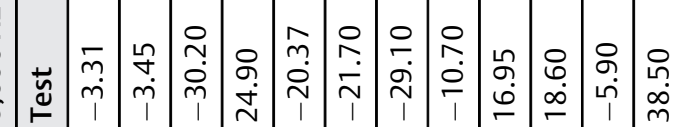

\begin{tabular}{|c|}
\hline $\begin{array}{l}\stackrel{n}{\Omega} \\
\text { م }\end{array}$ \\
\hline
\end{tabular}

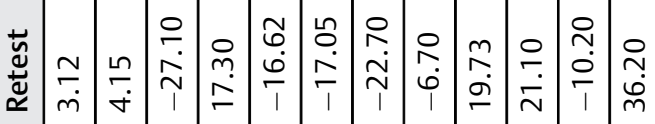

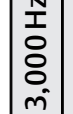

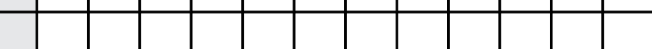

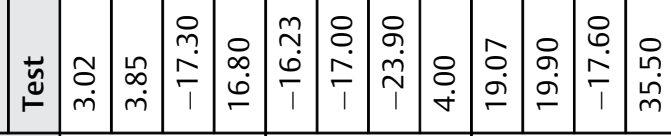

(1)

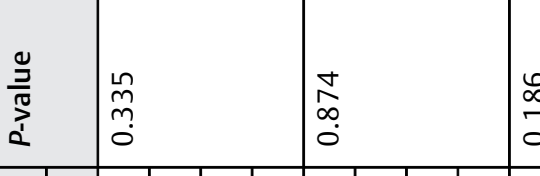

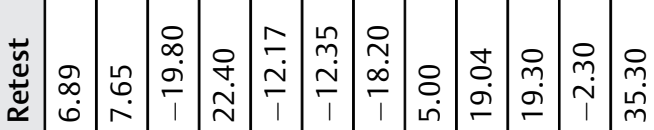

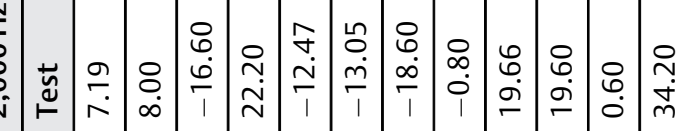

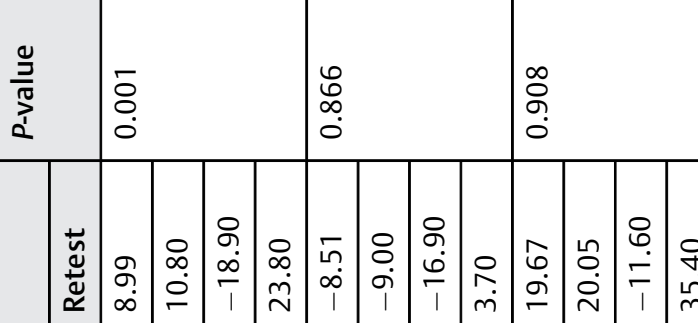

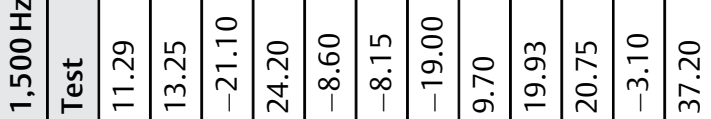

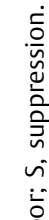




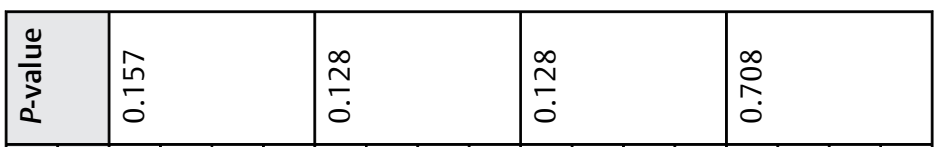

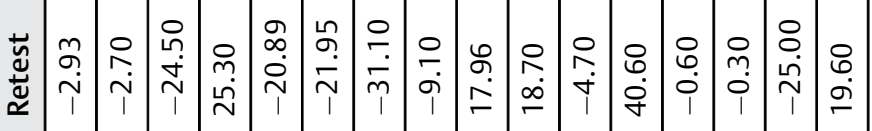

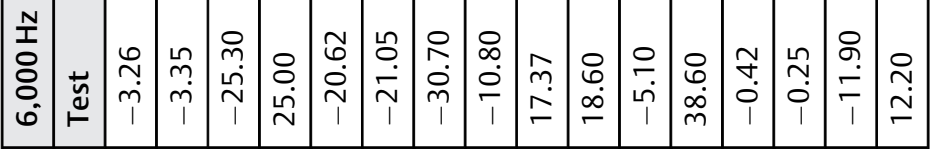

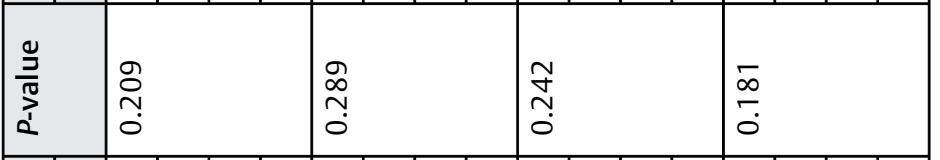

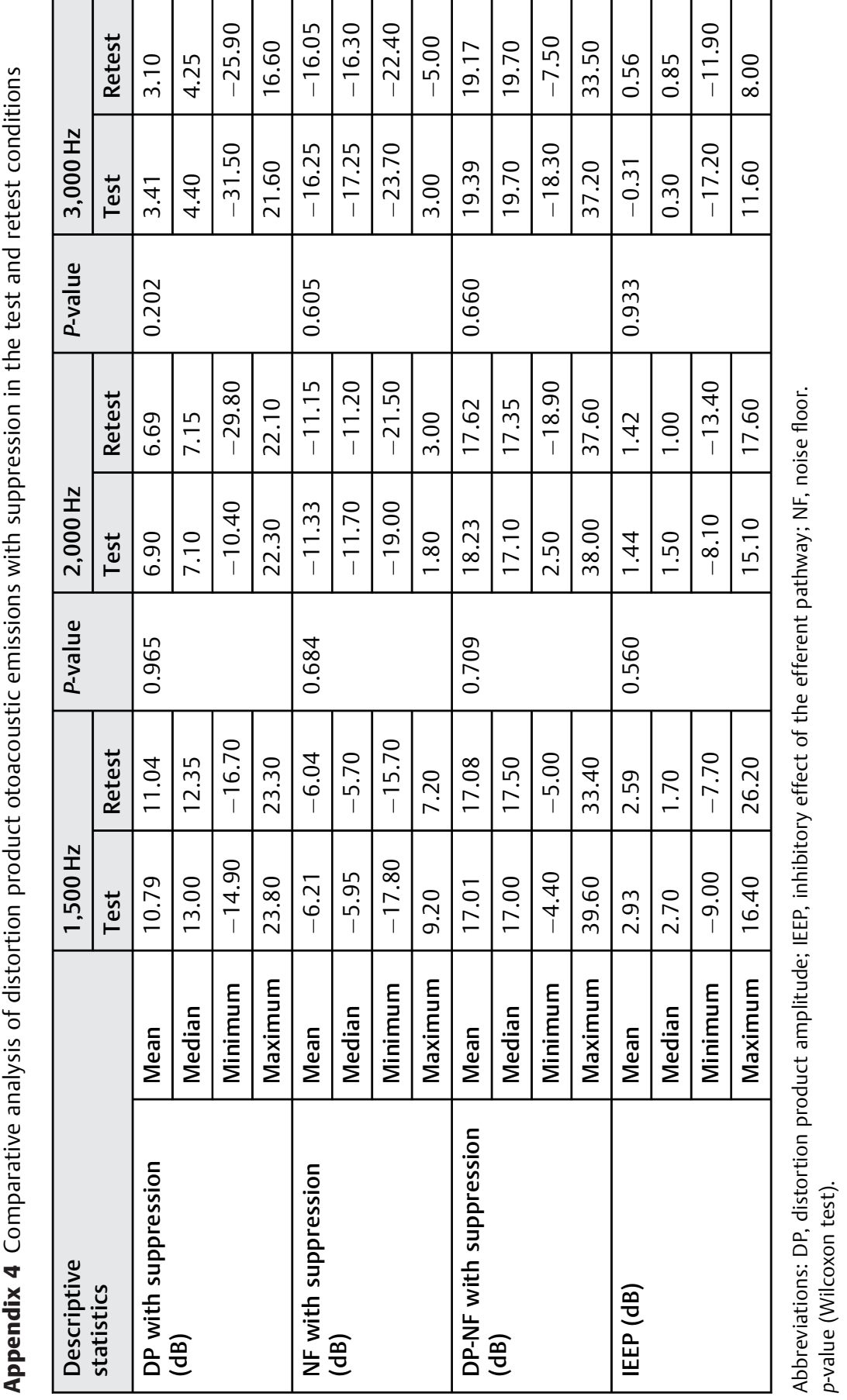

